\section{REFERENCES}

1. Mei-Ling Hou, Chi-Hung Lin, Lie-Chwen Lin AND Tung-Hu Tsai The Drug-Drug Effects of Rhein on the Pharmacokinetics and Pharmacodynamics of Clozapine in Rat Brain Extracellular Fluid by In Vivo Microdialysis. Journal of Pharmacology and Experimental Therapeutics October 2015, 355 (1) 125-134; DOI: $10.1124 /$ jpet.115.225763
2. Clozaril (clozapine tablets) [product monograph] Dorval (QC): Novartis Pharmaceuticals Canada Inc; 2014 Aug 19

3. Guideline on bioanalytical method validation. Committee for Medicinal Products for Human Use (CHMP), 2011

\title{
A CASE OF METHANE POISONING
}

Article history:

Submitted 20 June 2019

Accepted 30 July 2019

\section{Evgeny K. Barinov ${ }^{1,2}$, Dmitriy V. Sundukov', Olga L. Romanowa ${ }^{1,3}$, Pavel O. Romodanovskiy ${ }^{2}$}

${ }^{1}$ RUDN University, Department of Forensic Medicine, Moscow, Russia ${ }^{2}$ Moscow State University of Medicine and Dentistry, Department of Forensic Medicine and Medical Law, Moscow, Russia

${ }^{3}$ Federal Research and Clinical Center of Intensive Care Medicine and Rehabilitology, Moscow, Russia

*Corresponding Author: olgpharm@yandex.ru

\section{PATIENTS AND METHODS}

A case of acute methane intoxication has been studied.

The corpse of Mr. R (38 years old) without signs of violent death was found in a manhole.

\section{RESULTS}

During external examination extensive purple lividity located on the back surface of the head, neck, on the upper third of the chest, trunk, upper and lower limbs was observed. There were numerous petechial hemorrhages on the cheeks and chin. There were also multiple petechial hemorrhages in the connective membranes of the eyes.

Autopsy was performed. The myocardium on the section was greyish-brown, flabby and dull. There were areas of uneven blood-filling. The walls of the coronary arteries were thickened. The walls of the interventricular branch of the left coronary artery was circularly thickened, the lumen in the middle third was narrowed to $10 \%$ due to the presence of fibrous plaques.

A differential diagnostics between cardiac death and methane intoxication was needed. The rate of death was estimated according to the scale proposed by Dmitriy V. Bogomolov and Vladimir A. Putintsev $[1,2]$.

In this case, the rate of death can be described as fulminant (duration up to 30 minutes).

This was confirmed by the following signs: extremely mild severity of brain edema, detected macro- scopically (significance index 0,29), fresh hemorrhages in the parenchyma of the lungs and brain (significance index 0,16), plethora of capillaries of internal organs, particularly into lungs and kidney cortex (significance index 0,19 ), the absence of the so-called signs of shock hemodynamics (significance index 0,24), absence of disseminated intravascular coagulation, or DIC syndrome (complete absence of microthrombi or their presence only within the body) and respiratory distress syndrome (index of importance to 0,19 ). Total significance index: 1,07 [1,2].

Histological study, including histological study of the heart and the lungs. was performed. The results of histological study of the myocardium were as follows: "... secondary cardiomyopathy with diffuse goitriferous cardiosclerosis, focal stromal lipomatosis with acute degenerative lesions of the myocardium. Atherofibrosis of coronary arteries". There were no areas of fragmentation of cardiomiocytes, which is typical for cardiovascular death.

The results of histological examination of the lungs were as follows: “... areas of emphysema”. Chemical analysis (gas chromatography) was performed. Methane was found in the blood and internal organs.

\section{CONCLUSION}

The forensic medical diagnosis was "methane intoxication", which was confirmed by the results of histological and forensic chemical study. Methane was revealed.

\section{REFERENCES}

1. Putintsev V.A., Bogomolov D.V., Bogomolova I.N., DENISOva O.P. Determination of duration and speed of dying according to morphological features (guidelines). Moscow: FGBU RTsSME; 2017: 32. [In Russ.]

2. Putincev V.A., Bogomolov D.V., Sundukov D.V. Morphological Characteristics of Different Rates of Dying. General Reanimatology. 2018;14(4):35-43. (In Russ.) DOI: 10.15360/1813-9779-2018-4-35-43 [In Russ., In Engl.]

3. Katritsis D.G, Gersh B.J., Camm A J. A Clinical Perspective On Sudden Cardiac Death. Arrhythmia \& Electrophysiology Review 2016;5(3):177-82 